PREPARED FOR THE U.S. DEPARTMENT OF ENERGY, UNDER CONTRACT DE-AC02-76CH03073

PPPL-3840

PPPL-3840

UC-70

Investigations of Low and Moderate Harmonic

Fast Wave Physics on CDX-U

by

J. Spaleta, R. Majeski, C.K. Phillips, R.J. Dumont, R. Kaita,

V. Soukhanovskii, and L. Zakharov

July 2003

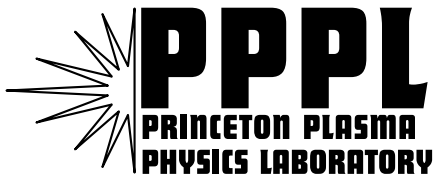

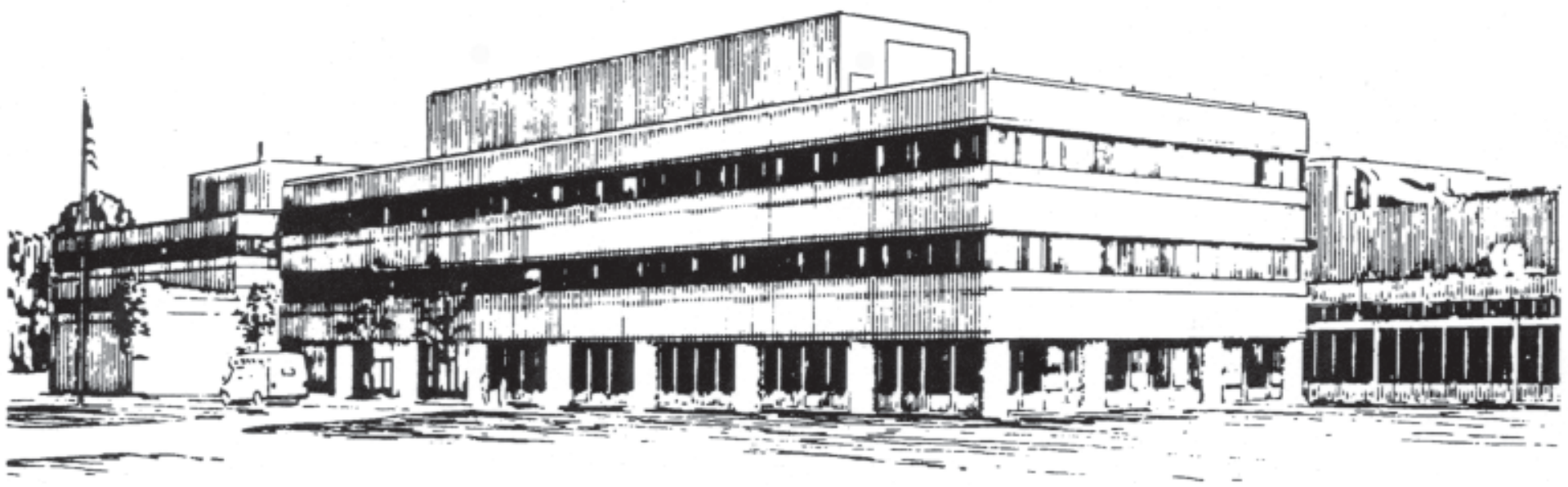

PRINCETON PLASMA PHYSICS LABORATORY PRINCETON UNIVERSITY, PRINCETON, NEW JERSEY 


\section{PPPL Reports Disclaimer}

This report was prepared as an account of work sponsored by an agency of the United States Government. Neither the United States Government nor any agency thereof, nor any of their employees, makes any warranty, express or implied, or assumes any legal liability or responsibility for the accuracy, completeness, or usefulness of any information, apparatus, product, or process disclosed, or represents that its use would not infringe privately owned rights. Reference herein to any specific commercial product, process, or service by trade name, trademark, manufacturer, or otherwise, does not necessarily constitute or imply its endorsement, recommendation, or favoring by the United States Government or any agency thereof. The views and opinions of authors expressed herein do not necessarily state or reflect those of the United States Government or any agency thereof.

\section{Availability}

This report is posted on the U.S. Department of Energy's Princeton Plasma Physics Laboratory Publications and Reports web site in Fiscal Year 2003. The home page for PPPL Reports and Publications is: http://www.pppl.gov/pub_report/

DOE and DOE Contractors can obtain copies of this report from:

U.S. Department of Energy

Office of Scientific and Technical Information

DOE Technical Information Services (DTIS)

P.O. Box 62

Oak Ridge, TN 37831

Telephone: (865) 576-8401

Fax: (865) 576-5728

Email: reports@adonis.osti.gov

This report is available to the general public from:

National Technical Information Service

U.S. Department of Commerce

5285 Port Royal Road

Springfield, VA 22161

Telephone: $1-800-553-6847$ or

(703) $605-6000$

Fax: (703) 321-8547

Internet: http://www.ntis.gov/ordering.htm 


\title{
Investigations of Low and Moderate Harmonic Fast Wave Physics on CDX-U ${ }^{1}$
}

\author{
J. Spaleta ${ }^{\dagger}$, R. Majeski ${ }^{\dagger}$, C. K. Phillips ${ }^{\dagger}$, R. J. Dumont ${ }^{* \dagger}$, R. Kaita ${ }^{\dagger}$, V. \\ Soukhanovskii ${ }^{\dagger}$, L. Zakharov ${ }^{\dagger}$ \\ $\dagger$ Princeton Plasma Physics Laboratory, Princeton, NJ 08543-0451 \\ * Association Euratom-CEA sure la Fusion Controlee, F-13108 St Paul lez, Durance, France
}

\begin{abstract}
Third harmonic hydrogen cyclotron fast wave heating studies are planned in the near term on CDX-U to investigate the potential for bulk ion heating. In preparation for these studies, the available RF power in CDX-U has been increased to $0.5 \mathrm{MW}$. The operating frequency of the CDX-U RF transmitter was lowered to operate in the range of $8-10$ $\mathrm{MHz}$, providing access to the ion harmonic range $2 \Omega \sim 4 \Omega$ in hydrogen. A similar regime is accessible for the $30 \mathrm{MHz}$ RF system on NSTX, at 0.6 Tesla in hydrogen. Preliminary computational studies over the plasma regimes of interest for NSTX and CDX-U indicate the possibility of strong localized absorption on bulk ion species.
\end{abstract}

\section{INTRODUCTION}

The physics of the low harmonic fast wave regime has been studied extensively in tokamak environments, but is largely unexplored for ST's which typically have a high dielectric constant and a higher ion beta than tokamaks. In this regime mode conversion to the IBW may become significant [1]. It has been suggested that third harmonic fast wave heating could be used for bulk ion heating in reactor scale tokamak plasmas [2]. However, little work has been done to examine the applicability of third harmonic ion cyclotron heating in the ST geometry. The two strap phasable antenna on CDX-U provides an excellent opportunity to investigate the low ion cyclotron harmonic regime of ST wave physics. Figure 1 provides an overview of the CDX-U geometry and typical operational parameters. The CDX-U operation parameter space allows for the investigation of second, third and fourth hydrogen cyclotron harmonics in both on-axis and off-axis scenarios. A similar third hydrogen harmonic regime is accessible in NSTX at 0.6 Telsa toroidal field.

1) Work supported in part by D.o.E Fusion Science Fellowship. 
CDX-Parameters:

- $R_{o}=34 \mathrm{~cm}$

- $a=22 \mathrm{~cm}$

- $b=35 \sim 38 \mathrm{~cm}$

- $\kappa=b / a=1.55 \sim 1.7$

- triangularly $=0.2 \sim 0.4$

- $B_{T 0}=2.3 \mathrm{kG}$

- $I_{p} \sim 80 \mathrm{kA}$

- $n_{e 0} \sim 4 \times 10^{19} \mathrm{~m}^{-3}$

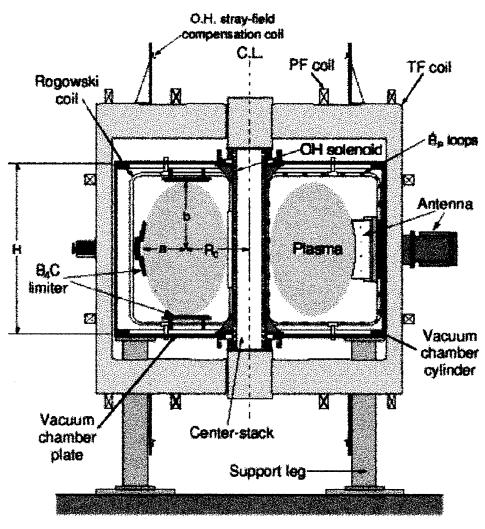

- $T_{e 0} \sim 100 \mathrm{eV}$

FIGURE 1. Cut-away view of CDX-U, with typical operational parameters

\section{NUMERICAL SIMULATIONS}

Two numerical simulation codes, CRF [3] and METS [4], were used to explore the feasibility of low harmonic fast wave power absorption. Both codes are 1-D slab plasma models which include a toroidal geometry induced radial $k_{z}$ up shift. CRF calculates solutions to the full hot plasma dispersion relation through the entire plasma region. METS solves for the wave fields to all orders in $k_{\perp} \rho_{i}$ and produces a power absorption profile for each species present in the plasma.

Figure 2 provides an example of the CRF generated plasma dispersion relation for typical CDX-U plasma parameters, with the radial location of the hydrogen and deuterium cyclotron resonant layers highlighted. Using a simple model for wave attenuation of a ray launched radially inward, $P_{\text {loss }}(r)=1-\exp \left[-2 \int_{0}^{r} \operatorname{Im}\left(k_{\perp}(x)\right) d x\right]$, one can estimate the power attenuation profile. The attenuation profile in Figure 3 indicates the potential for localized absorption in the typical CDX-U 90\% H / 10\% D plasmas near the hydrogen ion cyclotron harmonics. Results in a pure hydrogen plasma have similar localized behavior near the hydrogen cyclotron harmonics, suggesting that the minority species plays a negligible role in the fast wave damping process near the hydrogen harmonics.

METS was subsequently employed to obtain more detailed information about the absorbed power split between species, and to determine how much of the fast wave energy propagated onto the IBW branch. Figure 4 shows the power absorption profiles calculated by METS for a CDX-U relevant plasma, with the third hydrogen harmonic located on-axis. METS has been used to explore the applicability of third ion cyclotron harmonic heating in larger spherical tori. Figure 5 shows the fast wave power absorbed on the third hydrogen harmonic located at the magnetic axis as a function of ion beta for a target $90 \% \mathrm{H} / 10 \% \mathrm{D}$ plasma in NSTX and NSST relevant parameter regimes. The $\beta_{i o n}$ scans indicate that fast wave power absorption is strongly dependent on $\beta_{i o n}$. Because of the smaller physical size of the CDX-U plasma, the METS code has difficulty converging for some parameter choices. Work is underway to update the numerical algorithm in METS. Upon completion, similar $\beta_{i o n}$ studies will be performed 


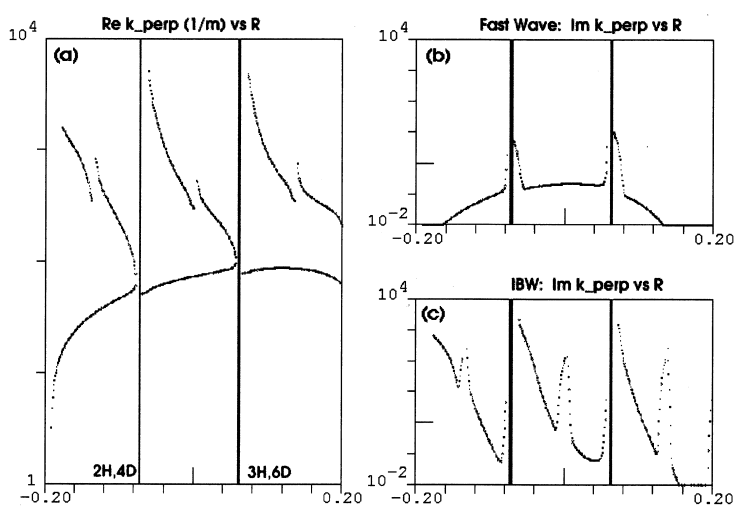

FIGURE 2. 1-D dispersion relation for a $90 \% \mathrm{H} / 10 \% \mathrm{D}$ plasma in CDX-U under typical operational parameters. Shown here is $k_{\perp}$ as a function of CDX-U minor radius, with the ion harmonic locations indicated and labeled. (a) Real part of $k_{\perp}$ for both fast wave and IBW. (b) Imaginary part of $k_{\perp}$ for the fast wave. (c) Imaginary part of $k_{\perp}$ for the IBW. Similar IBW and fast wave coupling features near the hydrogen harmonics occur for $100 \% \mathrm{H}$ plasma simulations as well, suggesting that the minority species is not critical to the ion cyclotron heating mechanism

for CDX-U.

\section{CONCLUSIONS}

Numerical simulations, using CRF and METS 1-D codes, indicate that 3rd harmonic fast wave heating could lead to strongly localized single pass absorption on bulk ion species in ST geometries. Furthermore, simulations indicate power absorption is strongly dependent on $\beta_{i o n}$. Discrepancies between the different types of $\beta_{i o n}$ scans, temperature, density and magnetic field variations, suggests a more complicated relationship between these primary plasma parameters. Experimental studies on CDX-U to investigate third harmonic hydrogen absorption are planned to begin in the near future. Future work also

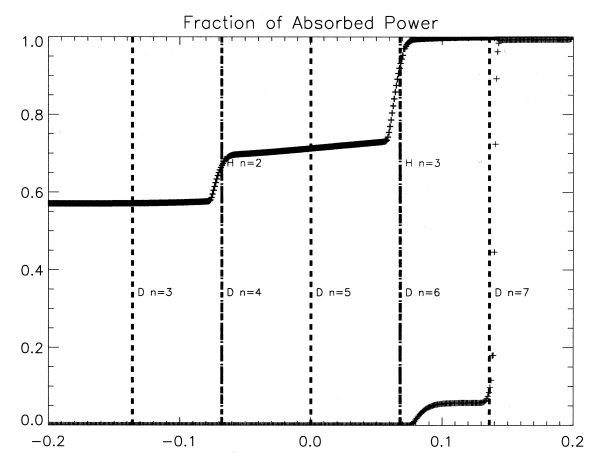

FIGURE 3. Fast wave attenuation calculation for a typical CDX-U plasma, based on the simple propagating ray approximation, $P_{\text {atten }}(r)=1-\exp \left[-2 \int_{0}^{r} \operatorname{Im}\left(k_{\perp}(x)\right) d x\right]$. Drops in wave power are localized to hydrogen harmonic regions, where the dispersion relation in Figure 2 indicates close coupling of IBW and fast wave branches. 

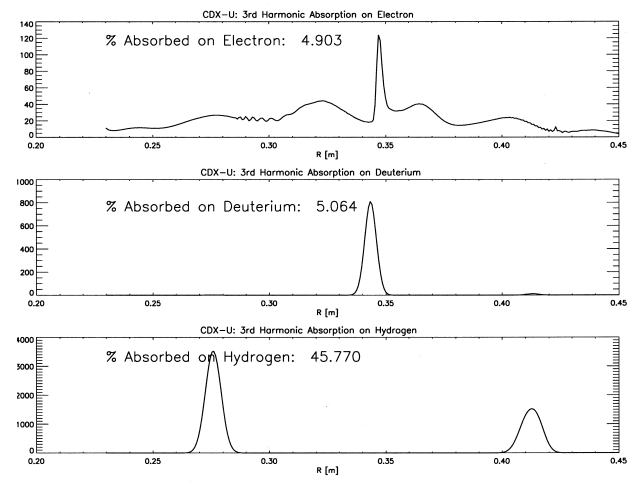

FIGURE 4. METS calculated by species power absorption profile in a $90 \% \mathrm{H} / 10 \% \mathrm{D}$ plasma for typical CDX-U operational parameters. Strong absorption on the dominant hydrogen at the 3rd and 2nd hydrogen harmonics.
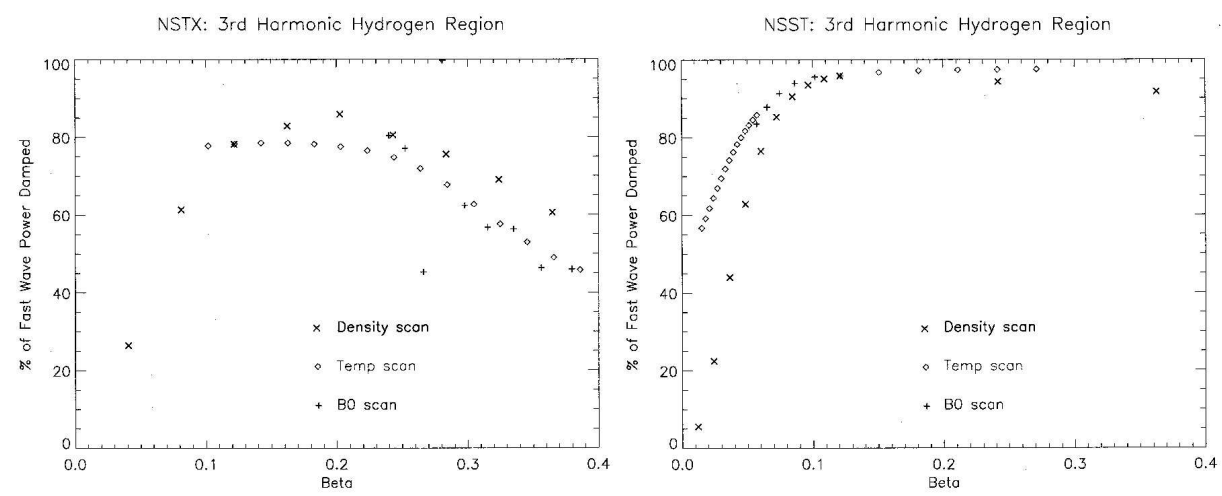

FIGURE 5. $\beta_{\text {ion }}$ scan comparisons between NSTX and NSST. Both show a strong dependence on $\beta_{i o n}$. (× variation in density, $\diamond$ variation in $T_{i},+$ variation in $B_{0}$ )

includes continued investigations of absorption parameter dependence via numerical simulations, as well as work towards an understanding of the applicability of analytical models for third harmonic heating such as [2] to the the ST regime.

\section{REFERENCES}

1. M. Ono, Phys. Plasmas 2 (1995).

2. D. G. Swanson, Phys. Fluids 28, 1800 (1985).

3. D. W. Ignat and M. Ono, Phys. Plasmas 2 (1995).

4. D. Smithe, Plasma Physics and Controlled Fusion 31, 1105 (1889). 


\section{External Distribution}

Plasma Research Laboratory, Australian National University, Australia

Professor I.R. Jones, Flinders University, Australia

Professor João Canalle, Instituto de Fisica DEQ/IF - UERJ, Brazil

Mr. Gerson O. Ludwig, Instituto Nacional de Pesquisas, Brazil

Dr. P.H. Sakanaka, Instituto Fisica, Brazil

The Librarian, Culham Laboratory, England

Mrs. S.A. Hutchinson, JET Library, England

Professor M.N. Bussac, Ecole Polytechnique, France

Librarian, Max-Planck-Institut für Plasmaphysik, Germany

Jolan Moldvai, Reports Library, Hungarian Academy of Sciences, Central Research Institute for Physics, Hungary

Dr. P. Kaw, Institute for Plasma Research, India

Ms. P.J. Pathak, Librarian, Institute for Plasma Research, India

Ms. Clelia De Palo, Associazione EURATOM-ENEA, Italy

Dr. G. Grosso, Instituto di Fisica del Plasma, Italy

Librarian, Naka Fusion Research Establishment, JAERI, Japan

Library, Laboratory for Complex Energy Processes, Institute for Advanced Study, Kyoto University, Japan

Research Information Center, National Institute for Fusion Science, Japan

Dr. O. Mitarai, Kyushu Tokai University, Japan

Dr. Jiangang Li, Institute of Plasma Physics, Chinese Academy of Sciences, People's Republic of China

Professor Yuping Huo, School of Physical Science and Technology, People's Republic of China

Library, Academia Sinica, Institute of Plasma Physics, People's Republic of China

Librarian, Institute of Physics, Chinese Academy of Sciences, People's Republic of China

Dr. S. Mirnov, TRINITI, Troitsk, Russian Federation, Russia

Dr. V.S. Strelkov, Kurchatov Institute, Russian Federation, Russia

Professor Peter Lukac, Katedra Fyziky Plazmy MFF UK, Mlynska dolina F-2, Komenskeho Univerzita, SK-842 15 Bratislava, Slovakia

Dr. G.S. Lee, Korea Basic Science Institute, South Korea

Institute for Plasma Research, University of Maryland, USA

Librarian, Fusion Energy Division, Oak Ridge National Laboratory, USA

Librarian, Institute of Fusion Studies, University of Texas, USA

Librarian, Magnetic Fusion Program, Lawrence Livermore National Laboratory, USA

Library, General Atomics, USA

Plasma Physics Group, Fusion Energy Research Program, University of California at San Diego, USA

Plasma Physics Library, Columbia University, USA

Alkesh Punjabi, Center for Fusion Research and Training, Hampton University, USA

Dr. W.M. Stacey, Fusion Research Center, Georgia Institute of Technology, USA

Dr. John Willis, U.S. Department of Energy, Office of Fusion Energy Sciences, USA

Mr. Paul H. Wright, Indianapolis, Indiana, USA 
The Princeton Plasma Physics Laboratory is operated by Princeton University under contract with the U.S. Department of Energy.

\author{
Information Services \\ Princeton Plasma Physics Laboratory \\ P.O. Box 451 \\ Princeton, NJ 08543
}

Phone: 609-243-2750

Fax: 609-243-2751

e-mail: pppl_info@pppl.gov

Internet Address: http://www.pppl.gov 